\title{
Impact of Immune-related Adverse Events on Nivolumab Efficacy in Patients With Upper Gastrointestinal Cancer
}

\author{
EISUKE BOOKA ${ }^{1}$, HIROTOSHI KIKUCHI ${ }^{1}$, RYOMA HANEDA ${ }^{1}$, WATARU SONEDA ${ }^{1}$, SANSHIRO KAWATA ${ }^{1}$, \\ TOMOHIRO MURAKAMI ${ }^{1}$, TOMOHIRO MATSUMOTO ${ }^{1}$, YOSHIHIRO HIRAMATSU $^{1,2}$ and HIROYA TAKEUCHI ${ }^{1}$ \\ ${ }^{1}$ Department of Surgery, Hamamatsu University School of Medicine, Shizuoka, Japan; \\ ${ }^{2}$ Department of Perioperative Functioning Care and Support, \\ Hamamatsu University School of Medicine, Shizuoka, Japan
}

\begin{abstract}
Background: The development of immune-related adverse events (irAEs) has been found to be associated with survival benefits in some cancers. However, data on the relation between irAEs and gastroesophageal adenocarcinoma (GEA) or esophageal squamous cell carcinoma (ESCC) are scarce. Patients and Methods: We retrospectively reviewed the data of 29 GEA and 21 ESCC patients treated with nivolumab. We investigated the impact of the development of irAEs in GEA and ESCC patients on best overall response and survival. Results: Patients with irAEs had significantly better best overall response, overall survival and progression-free survival than those without irAEs ( $p=0.007, p<0.001$ and $p=0.005$, respectively). Multivariate analyses identified an Eastern Cooperative Oncology Group performance status $\geq 2$ and the absence of an irAE as independent poor prognostic factors ( $p<0.001$ and 0.016, respectively). Conclusion: The development of irAEs has the potential to predict survival outcomes in patients with GEA and ESCC treated with nivolumab.
\end{abstract}

Gastroesophageal adenocarcinoma (GEA) and esophageal cancer show high malignant potential and poor prognosis, leading to the third and sixth leading cause of cancer-related mortality worldwide, respectively, and more than 1.2 million deaths altogether in 2020 (1). First-line doublet platinumbased chemotherapy is the standard of care for both

This article is freely accessible online.

Correspondence to: Hirotoshi Kikuchi, MD, Ph.D., Department of Surgery, Hamamatsu University School of Medicine, 1-20-1 Handayama, Higashi-ku, Hamamatsu, Shizuoka 431-3192, Japan. Tel: +81- 5343522779, Fax: +81 534352273, e-mail: kikuchih@hamamed.ac.jp

Key Words: irAE, gastroesophageal adenocarcinoma, esophageal squamous cell carcinoma, nivolumab. advanced or recurrent GEA and esophageal squamous cell carcinoma (ESCC), with the addition of trastuzumab in human epidermal growth factor receptor 2-positive GEA (2).

The recent development of immunotherapy has improved treatment outcomes for various types of cancer including GEA and ESCC. Nivolumab and pembrolizumab, monoclonal antibodies that target programmed cell death protein 1 (PD-1), have been approved for the treatment of advanced or recurrent unresectable GEA and ESCC on the basis of recent clinical trials demonstrating that these agents prolonged survival compared with cytotoxic chemotherapy $(2,3)$. Conversely, treatment with such immune-checkpoint inhibitors (ICIs) is accompanied by immune-related adverse events (irAEs) (4). The development of irAEs has been found to be associated with survival benefits in melanoma and non-small cell lung cancer, suggesting that an early onset of irAEs might be predictive of a better outcome of treatment with ICIs, and that the prompt management of irAEs could prolong the therapeutic period and maximize the therapeutic effect of ICIs (4). However, data on the relationships between irAEs and therapeutic effects of ICIs in GEA or ESCC are scarce (5).

We hypothesized that the development of irAEs in patients with GEA and ESCC treated with ICIs may be predictive of their better survival compared with those without irAEs. In this regard, this study aimed to investigate the impact of irAEs on survival in patients with advanced or recurrent GEA and ESCC treated with nivolumab.

\section{Patients and Methods}

Patients. We retrospectively collected data from the electronic medical records of all patients with advanced or recurrent GEA and ESCC who were treated with nivolumab at the Department of Surgery, Hamamatsu University School of Medicine. Nivolumab was initially administered to patients with GEA in November 2017, and to patients with ESCC in October 2018 in our institute. The end of the follow-up period was April 24, 2021. All procedures were conducted in accordance with institutional and national standards 
on human experimentation and with the Declaration of Helsinki of 1964 and its later versions. The ethics committee of Hamamatsu University School of Medicine approved this study. The board waived the requirement for written patient consent for the use of clinicopathological data, and all patients agreed to participate through an opt-out approach.

Procedure. Nivolumab was administered intravenously over $30 \mathrm{~min}$ at a dose of $240 \mathrm{mg}$ every 2 weeks until disease progression assessed by the investigator per Response Evaluation Criteria in Solid Tumors (RECIST), version 1.1, or unacceptable toxicity (6). Tumors were assessed using computed tomography per RECIST version 1.1 at baseline and every two months from the start of cycle 1 or at the development of symptoms. Adverse events were assessed throughout the treatment period and for 28 days after the end of treatment according to the National Cancer Institute Common Terminology Criteria for Adverse Event, version 5.0 (7).

Statistical analysis. Statistical analyses were performed using SPSS version 27.0 software (IBM Corp., Armonk, NY, USA). Categorical data were analyzed using Fisher's exact test or the chi-squared test as appropriate. Quantitative data were analyzed using the unpaired Student's $t$-test. Survival was analyzed using the Kaplan-Meier method and log-rank test. Univariate and multivariate comparisons of survival time were performed using Cox regression analysis. $p<0.05$ was considered statistically significant.

\section{Results}

Patient characteristics and irAE profile. The characteristics of all study participants are shown in Table I. There were 29 patients with GEA (58.0\%) including 3 esophagogastric junction carcinoma and 26 gastric cancer, and 21 patients with ESCC (42.0\%). Of all the patients, 13 patients $(26.0 \%)$ suffered from irAEs. Patients with irAEs had significantly better Eastern Cooperative Oncology Group (ECOG) performance status (PS) $(p=0.026)$, later therapy line $(p=0.044)$, greater number of administrations of nivolumab $(p=0.030)$ and more pharmacotherapy after nivolumab $(p=0.008)$ than those without irAEs. The irAE profile is shown in Table II. The most frequent irAE was pneumonitis.

Impact of irAE on best overall response (BOR) in patients treated with nivolumab. The BOR is shown in Table III. Of all patients, $7(14.0 \%)$ had a stable disease and $36(72.0 \%)$ had a progressive disease. No patients had complete or partial response to nivolumab. The tumor response was not evaluable in 7 patients $(14.0 \%)$. The BOR rates were compared between patients with and without irAEs except for 7 patients with unevaluable tumor response. Patients with irAEs $(n=9)$ had significantly better BOR than those without irAEs $(n=34)$ $(p=0.007)$.

Impact of irAEs on overall survival (OS) and progressionfree survival (PFS) in patients treated with nivolumab. The Kaplan-Meier curves for OS of all 50 patients according to
Table I. Clinicopathological characteristics.

\begin{tabular}{|c|c|c|c|c|}
\hline Characteristic & All patients & $\operatorname{irAE}(-)$ & $\operatorname{irAE}(+)$ & $p$-Value \\
\hline Total & 50 & $37(74.0 \%)$ & $13(26.0 \%)$ & \\
\hline Age (years) & $71(43-86)$ & $71(46-86)$ & $74(63-84)$ & 0.261 \\
\hline$<65$ & $9(18.0 \%)$ & $8(21.6 \%)$ & $1(7.7 \%)$ & \\
\hline$\geq 65$ & $41(82.0 \%)$ & $29(78.4 \%)$ & $12(92.3 \%)$ & \\
\hline Gender & & & & 0.148 \\
\hline Male & $39(78.0 \%)$ & $27(73.0 \%)$ & $12(92.3 \%)$ & \\
\hline Female & $11(22.0 \%)$ & $10(27.0 \%)$ & $1(7.7 \%)$ & \\
\hline ECOG PS & & & & 0.026 \\
\hline$\leq 1$ & $39(78.0 \%)$ & $26(70.3 \%)$ & $13(100 \%)$ & \\
\hline$\geq 2$ & $11(22.0 \%)$ & $11(29.7 \%)$ & $0(0 \%)$ & \\
\hline Tumor location & & & & 0.275 \\
\hline Esophagus & $21(42.0 \%)$ & $18(48.6 \%)$ & $3(23.1 \%)$ & \\
\hline $\begin{array}{l}\text { Esophagogastric } \\
\text { junction }\end{array}$ & $3(6.0 \%)$ & $2(5.4 \%)$ & $1(7.7 \%)$ & \\
\hline Stomach & $26(52.0 \%)$ & $17(45.9 \%)$ & $9(69.2 \%)$ & \\
\hline History of surgery & & & & 0.648 \\
\hline Yes & $32(64.0 \%)$ & $23(62.2 \%)$ & $9(69.2 \%)$ & \\
\hline No & $18(36.0 \%)$ & $14(37.8 \%)$ & $4(30.8 \%)$ & \\
\hline Histology & & & & 0.108 \\
\hline $\begin{array}{l}\text { Squamous cell } \\
\text { carcinoma }\end{array}$ & $21(42.0 \%)$ & $18(48.6 \%)$ & $3(23.1 \%)$ & \\
\hline Adenocarcinoma & $29(58.0 \%)$ & $19(51.4 \%)$ & $10(76.9 \%)$ & \\
\hline $\begin{array}{l}\text { Number of organs } \\
\text { with metastases }\end{array}$ & & & & 0.856 \\
\hline$\leq 1$ & $28(56.0 \%)$ & $21(56.8 \%)$ & $7(53.8 \%)$ & \\
\hline$\geq 2$ & $22(44.0 \%)$ & $16(43.2 \%)$ & $6(46.2 \%)$ & \\
\hline \multicolumn{5}{|l|}{ Site of metastases } \\
\hline Lymph node & $26(52.0 \%)$ & $17(45.9 \%)$ & $9(69.2 \%)$ & 0.148 \\
\hline Peritoneum & $21(42.0 \%)$ & $15(40.5 \%)$ & $6(46.2 \%)$ & 0.724 \\
\hline Lung & $11(22.0 \%)$ & $8(21.6 \%)$ & $3(23.1 \%)$ & 0.913 \\
\hline Liver & $8(16.0 \%)$ & $6(16.2 \%)$ & $2(15.4 \%)$ & 0.944 \\
\hline Bone & $5(10.0 \%)$ & $4(10.8 \%)$ & $1(7.7 \%)$ & 0.747 \\
\hline Therapy line & & & & 0.044 \\
\hline $2^{\text {nd }}$ & $9(18.0 \%)$ & $8(21.6 \%)$ & $1(7.7 \%)$ & \\
\hline $3^{\text {rd }}$ & $30(60.0 \%)$ & $24(64.9 \%)$ & $6(46.2 \%)$ & \\
\hline$\geq 4^{\text {th }}$ & $11(22.0 \%)$ & $5(13.5 \%)$ & $6(46.2 \%)$ & \\
\hline $\begin{array}{l}\text { Number of } \\
\text { administrations }\end{array}$ & & & & 0.030 \\
\hline$\leq 4$ & $38(76.0 \%)$ & $31(83.8 \%)$ & $6(46.2 \%)$ & \\
\hline$\geq 5$ & $12(24.0 \%)$ & $6(16.2 \%)$ & $7(53.8 \%)$ & \\
\hline $\begin{array}{l}\text { Pharmacotherapy } \\
\text { after nivolumab }\end{array}$ & & & & 0.008 \\
\hline Yes & $16(32.0 \%)$ & $8(21.6 \%)$ & & \\
\hline No & $34(68.0 \%)$ & $29(78.4 \%)$ & $5(38.5 \%)$ & \\
\hline
\end{tabular}

Age is presented as median (range). irAE: Immune-related adverse event; ECOG: Eastern Cooperative Oncology Group; PS: performance status.

the incidence of irAEs are shown in Figure 1A. Patients with irAEs $(n=13)$ had significantly better OS than those without irAEs $(n=37)(p<0.001)$. Subgroup analysis revealed that patients with GEA and irAEs $(n=10)$ had significantly better OS than those without irAEs $(n=19)$ (Figure 1B, $p<0.001)$. OS was comparable between patients with ESCC with irAEs $(n=3)$ and those without irAEs $(n=18)$ (Figure 1c, $p=0.309)$. 
Table II. Immune-related adverse events according to category and grade.

\begin{tabular}{lccc}
\hline Category & Total $(\mathrm{n}=50)$ & Grade 1-2 & Grade 3-4 \\
\hline Any & $13(26.0 \%)$ & $9(18.0 \%)$ & $5(10.0 \%)$ \\
$\begin{array}{l}\text { Pneumonitis } \\
\text { Endocrine }\end{array}$ & $5(10.0 \%)$ & $4(8.0 \%)$ & $1(2.0 \%)$ \\
$\quad \begin{array}{l}\text { Thyroiditis/ } \\
\text { hypothyroidism }\end{array}$ & $3(6.0 \%)$ & $2(4.0 \%)$ & $1(2.0 \%)$ \\
$\quad$ Hypophysitis & $1(2.0 \%)$ & $0(0 \%)$ & $1(2.0 \%)$ \\
$\quad$ ACTH deficiency & $1(2.0 \%)$ & $0(0 \%)$ & $1(2.0 \%)$ \\
Gastrointestinal & & & \\
$\quad$ Diarrhea/colitis & $3(6.0 \%)$ & $1(2.0 \%)$ & $2(4.0 \%)$ \\
$\quad$ Mucositis & $1(2.0 \%)$ & $0(0 \%)$ & $1(2.0 \%)$ \\
Skin & $1(2.0 \%)$ & $1(2.0 \%)$ & $0(0 \%)$ \\
$\quad$ Rash & & & \\
\hline
\end{tabular}

ACTH: Adrenocorticotropic hormone.

The Kaplan-Meier curves for progression-free survival (PFS) of all 50 patients according to the incidence of irAEs are shown in Figure 2A. Patients with irAEs $(n=13)$ had significantly better PFS than those without irAEs $(n=37)$ $(p=0.005)$. Subgroup analysis revealed that PFS was significantly better in patients with irAEs than in those without irAEs in both GEA ( $n=10$ vs. 19, Figure 2B, $p=0.032$ ) and $\operatorname{ESCC}(n=3$ vs. 18 , Figure $2 \mathrm{C}, p=0.012$ ).

Prognostic factors predicting poor survival in patients treated with nivolumab. Univariate analysis revealed that an ECOG PS $\geq 2$ and the absence of irAEs were clinically important factors affecting the OS of patients with GEA and ESCC treated with nivolumab. On multivariate analysis, an ECOG PS $\geq 2$ [hazard ratio $(\mathrm{HR})=17.931 ; 95 \%$ confidence interval $(\mathrm{CI})=4.964-64.773 ; p<0.001]$ and the absence of irAEs $[\mathrm{HR}=7.299 ; 95 \% \mathrm{CI}=1.456-37.037 ; p=0.016]$ were identified as independent poor prognostic factors (Table IV).

\section{Discussion}

The development of irAEs has been found to be associated with survival benefits in melanoma, non-small cell lung cancer, renal cell carcinoma, and very recently in gastric cancer (5, 8-13). However, to date, the association between irAEs and the prognosis with esophageal cancer has remained unknown. In the present study, we first showed that the development of irAEs is associated with better PFS in patients with ESCC who received ICIs, and that the impact of irAEs could differ between GEA and ESCC. We previously performed a comprehensive characterization of genomic alterations in ESCC and esophageal adenocarcinoma (EAC), and showed that EAC was genetically different from ESCC and proved to be the same as gastric adenocarcinoma (14). In
Table III. Best overall response to nivolumab.

\begin{tabular}{lcccc}
\hline $\begin{array}{l}\text { Best overall } \\
\text { response }\end{array}$ & All patients & irAE (-) & irAE (+) & $p$-Value \\
\hline Stable disease & $7(14.0 \%)$ & $3(8.1 \%)$ & $4(30.8 \%)$ & 0.007 \\
Progressive disease & $36(72.0 \%)$ & $31(83.8 \%)$ & $5(38.5 \%)$ & \\
Not evaluable & $7(14.0 \%)$ & $3(8.1 \%)$ & $4(30.8 \%)$ & \\
\hline
\end{tabular}

irAE: Immune-related adverse event.

Table IV. Results of univariate and multivariate analyses showing factors affecting the overall survival.

\begin{tabular}{|c|c|c|c|c|}
\hline Variable & $\begin{array}{c}\text { Univariate } \\
p \text {-Value }\end{array}$ & $\begin{array}{c}\text { Multivariate } \\
p \text {-Value }\end{array}$ & $\begin{array}{l}\text { Hazard } \\
\text { ratio }\end{array}$ & $95 \% \mathrm{CI}$ \\
\hline Age $(\geq 65$ vs. $<65)$ & 0.731 & 0.492 & 1.424 & $0.519-3.906$ \\
\hline Sex (male $v s$. female) & 0.428 & 0.566 & 1.357 & $0.478-3.861$ \\
\hline $\begin{array}{l}\text { Histology (squamous } \\
\text { cell carcinoma vs. } \\
\text { adenocarcinoma) }\end{array}$ & 0.791 & 0.611 & 1.272 & $0.503-3.226$ \\
\hline $\begin{array}{l}\text { Number of organs } \\
\text { with metastases } \\
(\geq 2 \text { vs. } \leq 1)\end{array}$ & 0.547 & 0.613 & 1.279 & $0.492-3.322$ \\
\hline ECOG PS $(\geq 2 v s . \leq 1)$ & $<0.001$ & $<0.001$ & 17.931 & $4.964-64.773$ \\
\hline irAE (no $v s$. yes) & $<0.001$ & 0.016 & 7.299 & $1.456-37.037$ \\
\hline
\end{tabular}

ECOG: Eastern Cooperative Oncology Group; PS: performance status; irAE: immune-related adverse event.

the present study, patients with irAEs had better PFS than those without irAEs in both subgroups of GEA and ESCC. Although there was no significant difference in OS between patients with ESCC with and without irAEs $(p=0.309)$, the number of patients with ESCC with irAEs $(n=3)$ was too small to compare with those without irAEs $(n=18)$ in this study. Taken together, our results suggest that the incidence of irAEs could be associated with better prognosis across cancer types. Moreover, patients with irAEs had a significantly better overall response compared to patients without irAEs, supporting the impact of irAEs on good prognosis.

The mechanisms underlying the association of irAEs with the outcome of treatment with PD-1 inhibitors are unknown. Previous studies showing an association of vitiligo with the outcome of immunotherapy in patients with melanoma have suggested that antigens shared between melanoma cells and normal melanocytes might contribute to this association (1517). Whether gastric cancer or esophageal cancer cells share antigen with tissues affected by irAEs in patients with GEA or ESCC remains to be determined. In the present study, 10 of 29 patients with GEA (34.5\%) and 3 of 21 patients with ESCC (14.3\%) developed irAEs and patients with GEA tended to develop more irAEs than those with ESCC. It was 

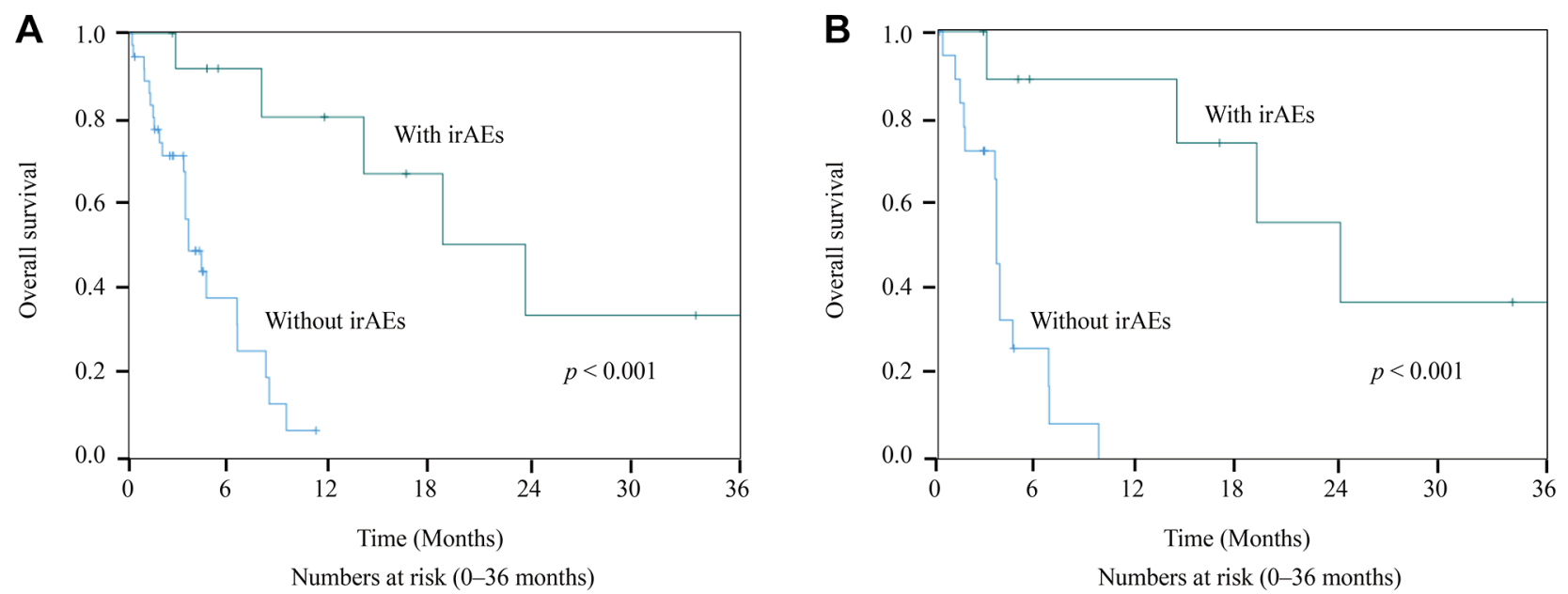

\begin{tabular}{cccccccc}
$\operatorname{irAE}(+)$ & 13 & 8 & 7 & 4 & 3 & 2 & 1 \\
\hline $\operatorname{irAE}(-)$ & 37 & 6 & 0 & 0 & 0 & 0 & 0
\end{tabular}

\begin{tabular}{cccccccc}
$\operatorname{irAE}(+)$ & 10 & 6 & 6 & 4 & 3 & 2 & 1 \\
\hline $\operatorname{irAE}(-)$ & 19 & 3 & 0 & 0 & 0 & 0 & 0
\end{tabular}

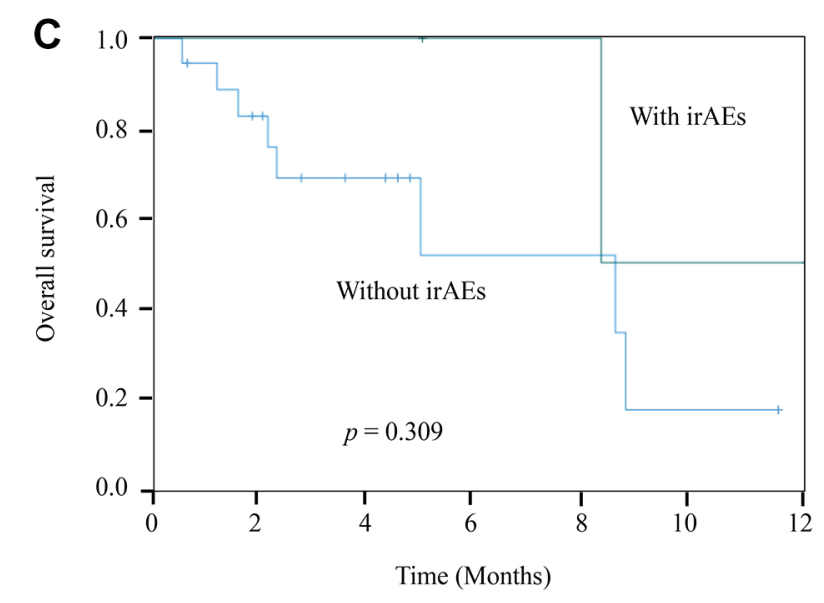

Numbers at risk (0-12 months)

\begin{tabular}{cccccccc}
$\operatorname{irAE}(+)$ & 3 & 3 & 3 & 2 & 2 & 1 & 1 \\
\hline $\operatorname{irAE}(-)$ & 18 & 13 & 8 & 3 & 3 & 1 & 0
\end{tabular}

Figure 1. Kaplan-Meier overall survival curves for (A) all patients, (B) patients with gastroesophageal adenocarcinoma and (C) patients with esophageal squamous cell carcinoma with and without immune-related adverse effects (irAEs).

suggested that irAEs might affect favorable prognosis regardless of cancer type, even if the irAE incidence rates depend on the type of cancer.

Patients with irAEs had significantly greater number of administrations of nivolumab, and more post-nivolumab therapy than those without irAEs. Multivariate analyses revealed that ECOG PS $\geq 2$ and the absence of an irAE were found to be significant poor prognostic factors. It is possible that irAEs could be managed more appropriately in patients with better PS, which increased the therapeutic opportunity after nivolumab and led to better outcomes. Adequate and intensive management of irAEs appears to be important to enable continuous post-nivolumab therapy and prolong survival. Matsumoto et al. reported that patients with a good PS had a better PFS and OS than those with poor PS (18). Patients with good PS might undergo nivolumab as early as possible to have good prognosis.

This study has several limitations. Most importantly, it was a retrospective single-center investigation with a small number of patients; the number of patients with ESCC with irAEs was particularly small. Second, the follow-up time was not long enough to permit us to fully address the long-term 

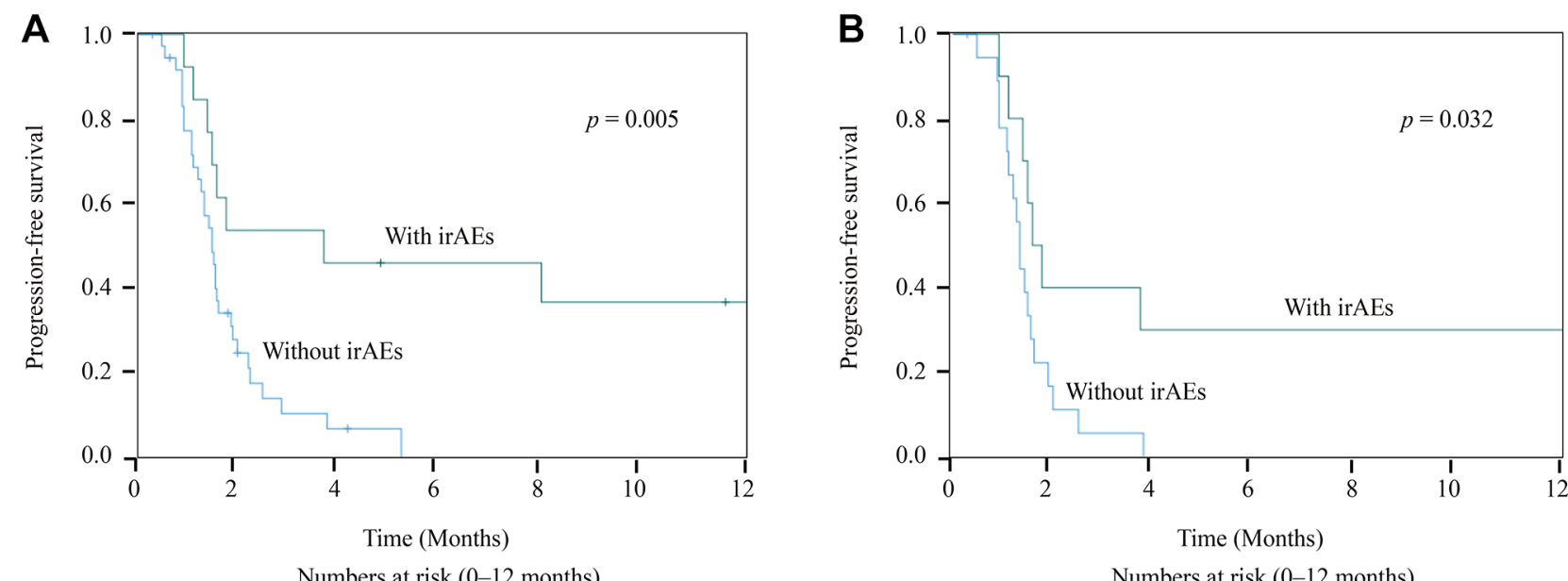

\begin{tabular}{cccccccc}
$\operatorname{irAE}(+)$ & 13 & 7 & 6 & 5 & 5 & 4 & 4 \\
\hline $\operatorname{irAE}(-)$ & 37 & 9 & 2 & 0 & 0 & 0 & 0
\end{tabular}

\begin{tabular}{cccccccc}
$\operatorname{irAE}(+)$ & 10 & 4 & 3 & 3 & 3 & 3 & 3 \\
\hline $\operatorname{irAE}(-)$ & 19 & 3 & 0 & 0 & 0 & 0 & 0
\end{tabular}

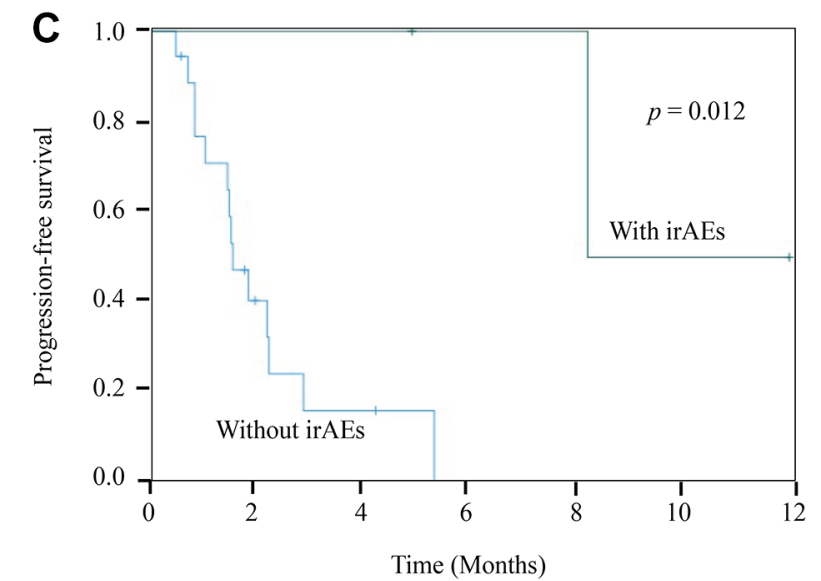

Numbers at risk (0-12 months)

\begin{tabular}{cccccccc}
$\operatorname{irAE}(+)$ & 3 & 3 & 3 & 2 & 2 & 1 & 1 \\
\hline $\operatorname{irAE}(-)$ & 18 & 6 & 2 & 0 & 0 & 0 & 0
\end{tabular}

Figure 2. Kaplan-Meier survival curves of progression-free survival for (A) all patients, (B) patients with gastroesophageal adenocarcinoma and (C) patients with esophageal squamous cell carcinoma with and without immune-related adverse effects (irAEs).

survival outcome. Third, the study may not have detected irAEs that were not explicitly documented in the medical record. Further studies with larger cohorts will be needed to confirm an association between the development of irAEs and the efficacy of nivolumab.

In conclusion, the development of irAEs has the potential to predict survival outcomes in patients with GEA and ESCC treated with nivolumab. The development of irAEs should be monitored carefully after starting nivolumab treatment to ensure longer survival in patients with GEA and ESCC.

\section{Conflicts of Interest}

The Authors declare that they have no conflicts of interest.

\section{Authors' Contributions}

E.B and H.K drafted and wrote the manuscript. E.B, H.K and H.T were involved in study design and data interpretation. E.B, H.K, R.H, W.S, S.K, T.M, T.M and Y.H were involved in the acquisition of the data. E.B analyzed the data. All Authors read and approved the manuscript. 


\section{Acknowledgements}

The Authors thank all the patients and medical staff at the institutions who contributed to this study.

\section{References}

1 Sung H, Ferlay J, Siegel RL, Laversanne M, Soerjomataram I, Jemal A and Bray F: Global Cancer Statistics 2020: GLOBOCAN estimates of incidence and mortality worldwide for 36 cancers in 185 countries. CA Cancer J Clin 71(3): 209249, 2021. PMID: 33538338. DOI: 10.3322/caac.21660

2 Smyth EC, Gambardella V, Cervantes A and Fleitas T: Checkpoint inhibitors for gastroesophageal cancers: dissecting heterogeneity to better understand their role in first-line and adjuvant therapy. Ann Oncol 32(5): 590-599, 2021. PMID: 33609722. DOI: 10.1016/j.annonc.2021.02.004

3 Boku N, Ryu MH, Kato K, Chung HC, Minashi K, Lee KW, Cho H, Kang WK, Komatsu Y, Tsuda M, Yamaguchi K, Hara H, Fumita S, Azuma M, Chen LT and Kang YK: Safety and efficacy of nivolumab in combination with S-1/capecitabine plus oxaliplatin in patients with previously untreated, unresectable, advanced, or recurrent gastric/gastroesophageal junction cancer: interim results of a randomized, phase II trial (ATTRACTION4). Ann Oncol 30(2): 250-258, 2019. PMID: 30566590. DOI: 10.1093/annonc/mdy540

4 Haratani K, Hayashi H, Chiba Y, Kudo K, Yonesaka K, Kato R, Kaneda H, Hasegawa Y, Tanaka K, Takeda M and Nakagawa K: Association of immune-related adverse events with nivolumab efficacy in non-small-cell lung cancer. JAMA Oncol 4(3): 374-378, 2018. PMID: 28975219. DOI: 10.1001/jamaoncol.2017.2925

5 Kono Y, Choda Y, Nakagawa M, Miyahara K, Ishida M, Kubota T, Seo K, Hirata T, Obayashi Y, Gotoda T, Moritou Y, Okikawa $\mathrm{Y}$, Iwamoto $\mathrm{Y}$ and Okada $\mathrm{H}$ : Association between immunerelated adverse events and the prognosis of patients with advanced gastric cancer treated with nivolumab. Target Oncol 16(2): 237-248, 2021. PMID: 33475927. DOI: 10.1007/s11523021-00790-w

6 Eisenhauer EA, Therasse P, Bogaerts J, Schwartz LH, Sargent D, Ford R, Dancey J, Arbuck S, Gwyther S, Mooney M, Rubinstein L, Shankar L, Dodd L, Kaplan R, Lacombe D and Verweij J: New response evaluation criteria in solid tumours: revised RECIST guideline (version 1.1). Eur J Cancer 45(2): 228-247, 2009. PMID: 19097774. DOI: 10.1016/j.ejca.2008.10.026

7 Common terminology criteria for adverse events (CTCAE) Version 5.0, 2017. Available at: https://ctep.cancer.gov/ protocolDevelopment/electronic_applications/ctc.htm\#ctc_50 [Last accessed on May 20, 2021]

8 Indini A, Di Guardo L, Cimminiello C, Prisciandaro M, Randon G, De Braud F and Del Vecchio M: Immune-related adverse events correlate with improved survival in patients undergoing anti-PD1 immunotherapy for metastatic melanoma. J Cancer Res Clin Oncol 145(2): 511-521, 2019. PMID: 30539281. DOI: $10.1007 / \mathrm{s} 00432-018-2819-\mathrm{x}$

9 Maillet D, Corbaux P, Stelmes JJ, Dalle S, Locatelli-Sanchez M, Perier-Muzet M, Duruisseaux M, Kiakouama-Maleka L, Freyer G, Boespflug A and Péron J: Association between immune-related adverse events and long-term survival outcomes in patients treated with immune checkpoint inhibitors. Eur J Cancer 132: 61-70, 2020. PMID: 32334337. DOI: 10.1016/j.ejca.2020.03.017
10 Owen DH, Wei L, Bertino EM, Edd T, Villalona-Calero MA, He K, Shields PG, Carbone DP and Otterson GA: Incidence, risk factors and effect on survival of immune-related adverse events in patients with non-small-cell lung cancer. Clin Lung Cancer 19(6): e893-e900, 2018. PMID: 30197259. DOI: 10.1016/ j.cllc.2018.08.008

11 Suo A, Chan Y, Beaulieu C, Kong S, Cheung WY, Monzon JG, Smylie M, Walker J, Morris D and Cheng T: Anti-PD1-induced immune-related adverse events and survival outcomes in advanced melanoma. Oncologist 25(5): 438-446, 2020. PMID: 32048768. DOI: 10.1634/theoncologist.2019-0674

12 Verzoni E, Cartenì G, Cortesi E, Giannarelli D, De Giglio A, Sabbatini R, Buti S, Rossetti S, Cognetti F, Rastelli F, Sobrero A, Turci D, Sternberg CN, Porta C, Cappuzzo F, Tortora G, Tassinari D, Panni S, Pazzola A, Surico G, Raimondi A, De Giorgi U, Procopio G and Italian Nivolumab Renal Cell Cancer Early Access Program group: Real-world efficacy and safety of nivolumab in previously-treated metastatic renal cell carcinoma, and association between immune-related adverse events and survival: the Italian expanded access program. J Immunother Cancer 7(1): 99, 2019. PMID: 30944023. DOI: 10.1186/s40425-019-0579-Z

13 Nakamura Y, Tanaka R, Asami Y, Teramoto Y, Imamura T, Sato S, Maruyama H, Fujisawa Y, Matsuya T, Fujimoto $M$ and Yamamoto A: Correlation between vitiligo occurrence and clinical benefit in advanced melanoma patients treated with nivolumab: A multi-institutional retrospective study. J Dermatol 44(2): 117-122, 2017. PMID: 27510892. DOI: 10.1111/1346-8138.13520

14 Booka E, Tsubosa Y, Yokota T, Mayanagi S, Ishii K, Urakami K, Ohshima K, Ohnami S, Nagashima T and Yamaguchi K: Whole exome sequencing and deep sequencing of esophageal squamous cell carcinoma and adenocarcinoma in Japanese patients using the Japanese version of the Genome Atlas, JCGA. Esophagus, 2021. PMID: 33826001. DOI: 10.1007/s10388-021-00835-Z

15 Hua C, Boussemart L, Mateus C, Routier E, Boutros C, Cazenave H, Viollet R, Thomas M, Roy S, Benannoune N, Tomasic G, Soria JC, Champiat S, Texier M, Lanoy E and Robert C: Association of vitiligo with tumor response in patients with metastatic melanoma treated with pembrolizumab. JAMA Dermatol 152(1): 45-51, 2016. PMID: 26501224. DOI: 10.1001/ jamadermatol.2015.2707

16 Sanlorenzo M, Vujic I, Daud A, Algazi A, Gubens M, Luna SA, Lin K, Quaglino P, Rappersberger $\mathrm{K}$ and Ortiz-Urda S: Pembrolizumab cutaneous adverse events and their association with disease progression. JAMA Dermatol 151(11): 1206-1212, 2015. PMID: 26222619. DOI: 10.1001/jamadermatol.2015.1916

17 Teulings HE, Limpens J, Jansen SN, Zwinderman AH, Reitsma JB, Spuls PI and Luiten RM: Vitiligo-like depigmentation in patients with stage III-IV melanoma receiving immunotherapy and its association with survival: a systematic review and metaanalysis. J Clin Oncol 33(7): 773-781, 2015. PMID: 25605840. DOI: $10.1200 / J C O .2014 .57 .4756$

18 Matsumoto T, Yamamoto Y, Kuriona Y, Okazaki U, Kimura S, Miura K, Tsuduki T, Watanabe T, Mastumoto Y and Takatani M: Efficacy and safety of nivolumab for advanced gastric cancer patients with poor performance statuses. BMC Cancer 20(1): 684, 2020. PMID: 32698781. DOI: 10.1186/s12885-020-07176-7

Received April 24, 2021

Revised May 18, 2021

Accepted May 21, 2021 